\title{
Improving UV Protection of Cotton Fabrics Dyed with Peristrophe bivalvis Extract using UV Absorber
}

\author{
Rachma Tia Evitasari ${ }^{\text {a, }, *}$, Edia Rahayuningsih ${ }^{\text {b,2 }}$ \\ ${ }^{a}$ Department of Chemical Engineering, Universitas Ahmad Dahlan, 55191 Yogyakarta, Indonesia \\ ${ }^{\mathrm{b}}$ Department of Chemical Engineering, Universitas Gadjah Mada, 55281 Yogyakarta, Indonesia \\ ${ }^{1}$ rachma.evitasari@che.uad.ac.id *; ${ }^{2}$ edia_rahayu@ugm.ac.id \\ * corresponding author
}

ARTICLE INFO

Article history

Received April 14, 2020

Revised June 17, 2020

Accepted June 18, 2020

Keywords

Natural dye

UV Absorber

UV Protection Factor

Peristrophe bivalvis

Dyeing

\section{ABSTRACT}

$U V$ radiation from the sun that constantly exposes the skin can cause skin damage such as sunburn and skin cancer. The damage from UV can be reduced by clothing. Increasing UV protection on cotton fabric can be done by adding UV absorbers. The effect of type, treatment, and concentration of $U V$ absorber on cotton dyed with phenoxazine natural dyes from Peristrophe bivalvis was studied. Two types of $U V$ absorber were used, benzophenone and benzotriazole. Concentrations of UV absorber used in this study ranging from $5 \%$ to $15 \%$ on weight of fabric applied on three treatments, before dyeing, after dyeing, and both. UV protection on the cotton fabric was expressed by the UV Protection Factor (UPF) value. Lightfastness, washing fastness and rubbing fastness were also performed using grayscale. The use of UV absorbers increases the UPF value of dyed cotton by before and after dyeing treatment. The best UPF value was achieved by adding benzotriazole with a concentration of $15 \%$ by before and after treatment resulting in a $U P F$ value of 5.45. The results of light fastness, washing fastness, and rubbing fastness ware also improved by the addition of UV absorber.

This is an open access article under the CC-BY-SA license.

\section{Introduction}

UV radiation from the sun that constantly exposes the skin can cause skin damage such as sunburn and skin cancer. Indonesia, a tropical country that is exposed to sunlight throughout the year, must be aware of the dangers of excessive sun exposure. But there are still many people who ignore the danger of excessive sun exposure.

This skin damage is caused by ultraviolet (UV) radiated by the sun. Ultraviolet light is electromagnetic radiation with short waves, shorter than visible light. UV wavelengths are at 100 $380 \mathrm{~nm}$, divided into three, UVC (100 - $280 \mathrm{~nm})$, UVB (280 - $320 \mathrm{~nm})$, and UVA (320 - $400 \mathrm{~nm})$. UVC cannot reach the surface of the earth because it is filtered in the stratosphere layer, so it is not harmful to humans. But UVA and UVB can reach the earth's surface, UVA can only be held in the stratosphere by $5 \%$ and UVB can be filtered up to $90 \%$ in the stratosphere [1].UVA which has a longer wavelength and low energy can cause pigmentation and premature aging of human skin. UVA can also penetrate window glass. While UVB is a high-energy UV and has a role in the formation of vitamin D. However, UVB can cause sunburn and lead to skin cancer [2], [3].

Clothing can reduce various dangers that can be caused by exposure to UV light. When UV radiation hits the fabric, it will be reflected, absorbed, and transmitted, as illustrated in Figure 1. Several factors affect the protective effect of the fabric against UV light, nature of the fabric, fabric surface, and fabric density [4], [5]. Besides, the protective effect of fabric can also be enhanced by 
the chemical processes carried out on the fabric, including dyeing and bleaching [6]-[9]. UV protection on the cotton fabric was expressed by the UV Protection Factor (UPF) value.

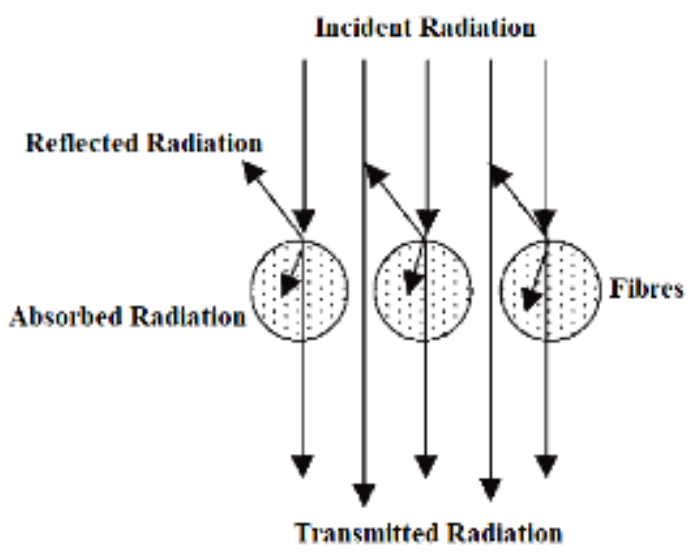

Fig. 1. Radiation in contact with a textile surface. [4]

Another method to increase UV fabric protection is by adding UV absorbers. UV absorber is a colorless organic compound that has a strong absorption at the ultraviolet range of $280-400 \mathrm{~nm}$. There are 2 types of UV absorbers, organic UV absorbers, such as benzophenone and benzotriazole, and inorganic $\mathrm{UV}$ absorbers such as $\mathrm{TiO}_{2}$ and $\mathrm{ZnO}$ [10]-[12].

The choice of fabric type and dyes, both synthetic and natural dyes, greatly influences the UV Protection Factor. Indonesian batik generally uses cotton fabric and natural dyes as its coloring. Cotton fabric has the lowest UV protection value compared to other types of fabric, such as wool and silk [13]. Whereas natural dyes generally have less lightfastness compared to synthetic dye. The use of natural dyes in the dyeing process can increase the UV Protection Factor compared to undyed cotton fabrics [14]-[16]. Even so, the UV protection of cotton fabrics dyed with natural dyes is still not satisfactory since the lightfastness value less than 2 in grayscale, which means it has poor performance [17].

In this study natural dyes from Peristrophe bivalvis known as noja in Indonesia are used as natural dyes that produce a red color. The dye pigment in Peristrophe bivalvis leaves which produce red color is phenoxazine, but chlorophyll and anthocyanin are also found in the leaves [18]. Phenoxazine pigments are generally found limited to insects and fungi [19]. Natural dye pigments contained in Peristrophe bivalvis leaves belong to the phenoxazine alkaloid group, they are peristrophine and perisbivalvine A [20]. Compared to other red-colored natural pigments, such as anthocyanin and brazilin, phenoxazine provides better stability to $\mathrm{pH}$ and oxidation [21]-[25]. The application of natural dyes from Peristrophe bivalvis leaves to dyed cotton fabrics has been carried out in previous studies by [26] with the result of sufficient fastness value.

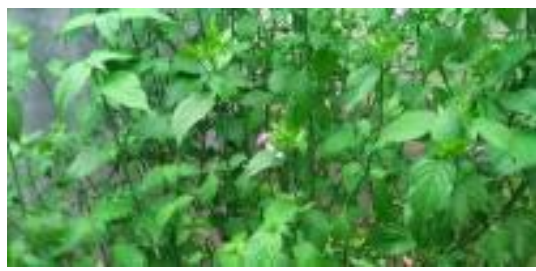

Fig. 2. Peristrophe bivalvis Leaves.

The purpose of this research is to study the effect of type, treatment, and concentration of UV absorber on cotton fabric dyed with phenoxazine from Peristrophe bivalvis leaves on the value of UV Protection Factor (UPF). UV absorbers used are benzophenone and benzotriazole. The UV absorber application process was carried out under 3 conditions, before dyeing, after dyeing, and both. These conditions can define if the UV absorber acts as a mordant to pick the pigment or will dissolve pigment Lightfastness, washing fastness, and rubbing fastness was also performed using grayscale. It is hoped that this research can be an alternative to improve the quality of Indonesian batik which protects the fabric from UV light. 


\section{Material and Method}

\subsection{Material}

This research used $100 \%$ bleached cotton fabric purchased from a local trader in Yogyakarta. Mordant used in this research, ferrous sulfate, was provided by the Gamaindigo workshop in Yogyakarta. Peristrophe bivalvis was grown and cultivated in Yogyakarta. UV absorbers (benzophenone and benzotriazole) were purchased from PT Justus Kimia Raya. The solvents such as aquadest, acetone, and ethanol were purchased from CV Progo Mulyo.

\subsection{Cotton Dyeing with Peristrophe bivalvis extract}

The dyeing method is based on previous research [26]. The dyeing process began with the premordanting process by dipping the cotton fabric in a ferrous sulfate solution with a concentration of 10.96 owf. $\%$ at $70{ }^{\circ} \mathrm{C}$ for 1 hour. Fabric that has been through the process of pre-mordanting process, then dyed with natural dye extracts from Peristrophe bivalvis leaves at a temperature of 61 ${ }^{\circ} \mathrm{C}$ for one hour, then dried. The fabric which has been dyed is then through a post-mordanting process with ferrous sulfate with a concentration of 10.96 owf. \% at room temperature for 30 minutes.

\subsection{UV Absorber treatment}

In the treatment before dyeing, the fabric that has been through a pre-mordanting process is then treated with a UV absorber. Variations in the types of UV absorbers used are benzophenone and benzotriazole. The cloth is dipped in a UV absorber solution with a concentration variation of 5\%, $10 \%$, and $15 \%$ of the weight of the fabric, at a temperature of $50{ }^{\circ} \mathrm{C}$ for 30 minutes, then washed and dried. In the treatment after dyeing, the fabric that has been through the post-mordanting process is then given a UV absorber treatment. The cloth is dipped in a UV absorber solution with a concentration variation of $5 \%, 10 \%$, and $15 \%$ on the weight of the fabric, at room temperature for 5 minutes, then washed and dried.

\subsection{Fastness Tests}

The dyed samples were tested according to Indonesian standard methods (SNI). The lightfastness was performed using SNI 08-0289-1989 method, washing fastness was carried out using SNI 080285-1989 method, and rubbing fastness was done using SNI 08-0288-1989 method. The results of fastness analysis were expressed as greyscale.

\subsection{UV Protection Factor (UPF) Analysis}

Dyed textile samples were analyzed by measuring the transmittance curve between $280 \mathrm{~nm}$ and $400 \mathrm{~nm}$ using Shimadzu Spectrophotometer UV-2401PC. The UV Protection Factor (UPF) values were calculated by the following Equation [11]:

$$
U P F=\frac{\sum_{290 \mathrm{~nm}}^{400 \mathrm{~nm}} E_{\lambda} S_{\lambda} \Delta \lambda}{\sum_{290 \mathrm{~nm}}^{400 \mathrm{~mm}} E_{\lambda} S_{\lambda} T_{\lambda} \Delta \lambda}
$$

where $S_{\lambda}$ is a spectrum $\left(\mathrm{Wm}^{2} \mathrm{~nm}^{-1}\right), \mathrm{E}_{\lambda}$ is response spectrum, $T_{\lambda}$ is transmittance value, and $\Delta \lambda$ is wavelength difference $(\mathrm{nm}) . \mathrm{E}_{\lambda}$ and $\mathrm{S}_{\lambda}$ data were taken from [27].

\section{Result and Discussion}

\subsection{Effects of Benzophenone UV Absorber Addition}

In this research, benzophenone is used on cotton fabric which is dyed with natural dyes from Peristrophe bivalvis extract to increase the value of UV Protection Factor. The UV absorber of the benzophenone group used in this study was 2,4-Dihydroxybenzophenone. Physically, there is no significant difference in color on the fabric with the addition of benzophenone. The colors of fabric samples with the addition of benzophenone in various treatments and concentrations are presented in Table 1. Data on the value of protection against ultraviolet rays (UPF) on fabrics dyed with natural 
dyes from Peristrophe bivalvis leaves with the addition of benzophenone UV absorbers are presented in Figure 3.

The addition of benzophenone to the cotton fabric which is dyed with natural dyes from Peristrophe bivalvis extract generally gives the result of an increase in the UPF value at each variation of the concentration of the benzophenone and its treatment process. In the benzophenone concentration variation, the greater the value of the benzophenone concentration, the better the UPF value, so that the protection of the fabric against ultraviolet light is better. The higher the concentration, the more even the UV Absorber spread in the fabric surface. This condition will lead to better protection and increasing UPF Value. UPF values rise with increasing benzophenone concentrations in each treatment adding benzophenone, both before dyeing, after dyeing, or both.

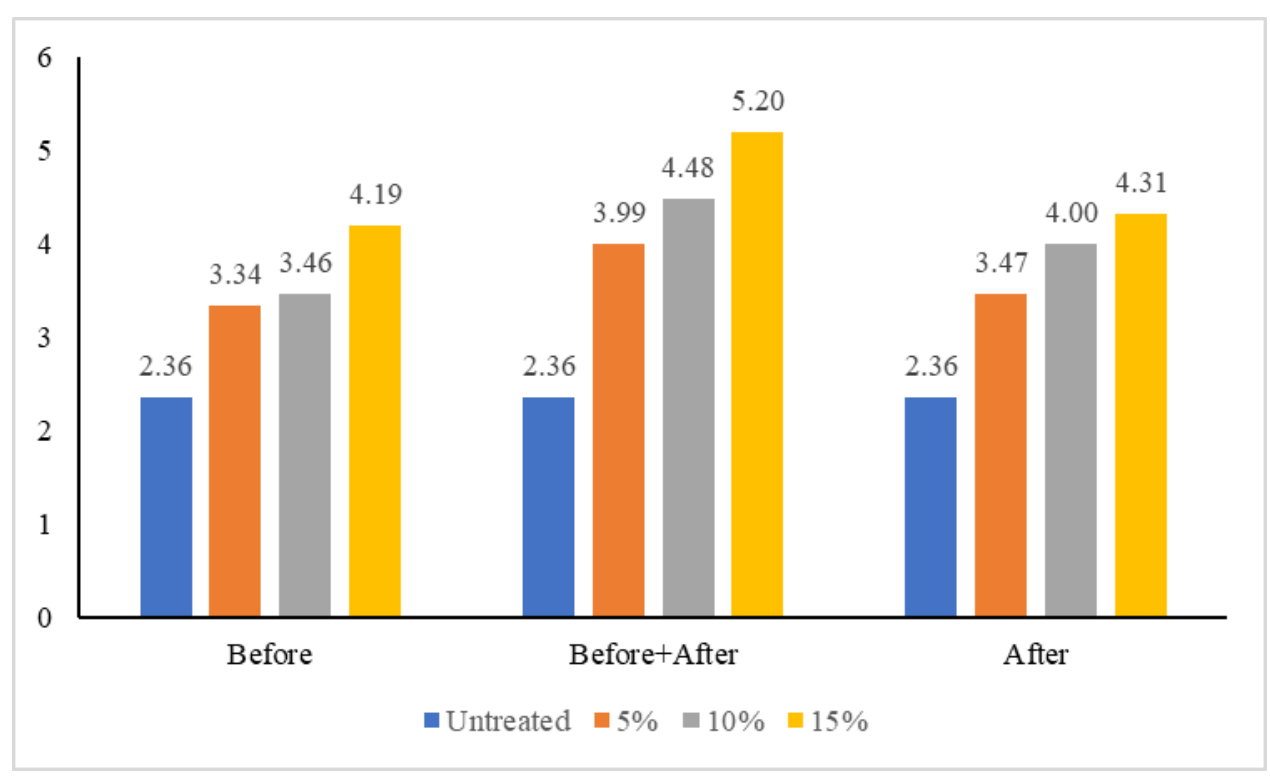

Fig. 3. UV Protection Factor in additions of Benzophenone.

The untreated sample has a UPF value of 2.36, the addition of benzophenone before dyeing with a concentration of 5\% gives an increase in the UPF value to 3.34 . This value is the lowest among UPF benzophenone values. The highest UPF increase was found in the addition of benzophenone concentration by $15 \%$ with the treatment at before and after the dyeing process by 5.2 , an increase in the UPF value by $120 \%$.

Shen [28] in his research using a UV absorber combination between benzophenone and triazine in cotton fabric using synthetic dyes stated that increasing the concentration of UV absorber would increase the UPF value. This is because benzophenone is a UV absorber that reactively forms covalent bonds with dyes, so the higher the concentration of benzophenone, the higher the UPF value produced [29], [30]. However, in this study, the increase in the UPF value with the addition of UV absorber was not as great as in the study conducted by Shen. In that study a UPF value increased from 6.9 becomes 21.1 (200\% increase), this difference occurs because this study used the natural dye of Peristrophe bivalvis extract, with phenoxazine dye as the main pigment. Natural dyes do not have as much reactivity as synthetic dyes, so the increase is lower only by $120 \%$.

UPF value increase also occurs in the variation of the treatment process of adding benzophenone UV. The highest UPF value has resulted from the addition of benzophenone treatment before and after dyeing, followed by treatment after dyeing, and the lowest UPF value in the treatment of adding benzophenone before the dyeing process. The difference in UPF values in the treatment before coloring and after dyeing is very small. This shows that the addition of benzophenone before dyeing does not significantly increase the absorption of dyes into the fabric. However, the treatment of adding benzophenone after the dyeing process increases the protective properties of the fabric against ultraviolet light.

The mechanism of the protection provided by the UV absorber against the fabric is photochemistry. In general, the mechanism of action of a UV absorber is to ward off ultraviolet light before it hits a dye pigment, then it is converted into vibrational energy in the UV absorber 
molecule. This vibrational energy is then converted into heat energy around it without degradation of the dye [31]-[33] so that the fabric is protected from ultraviolet light.

Table 1. The Shades of Dyed Cotton in Additions of Benzophenone

\begin{tabular}{|c|c|c|c|}
\hline Treatment & Conc. 5 owf.\% & Conc. 10 owf.\% & Conc. 15 owf.\% \\
\hline $\begin{array}{l}\text { Before } \\
\text { dyeing }\end{array}$ & $5 \%$-before & $10 \%$ - before & $15 \%$-before \\
\hline
\end{tabular}

After dyeing
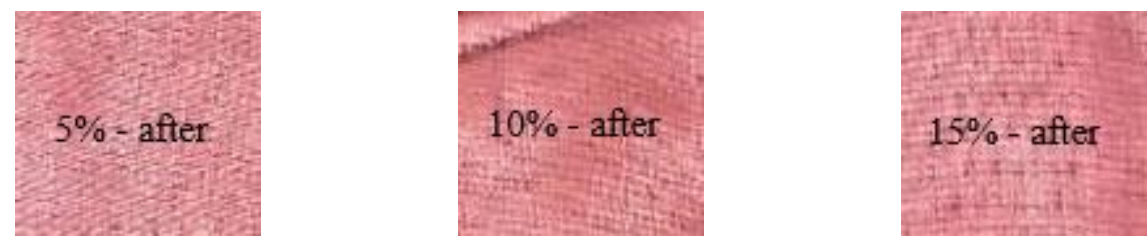

after dyeing
aftore and
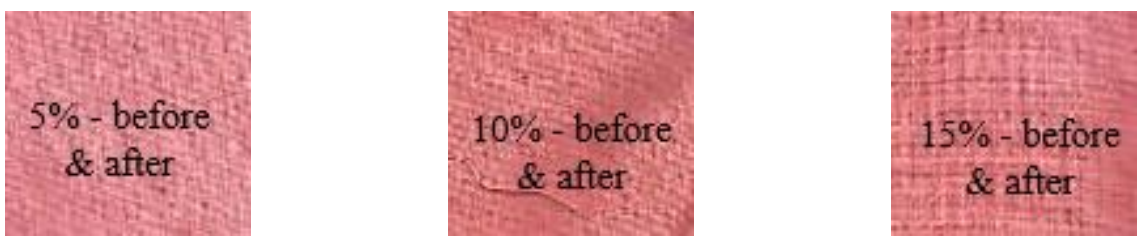

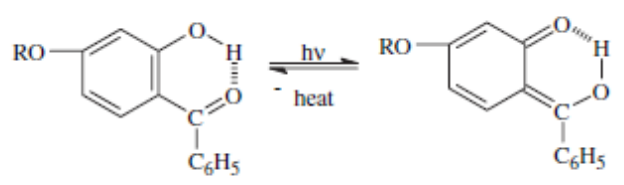

Fig. 4. Photochemistry mechanism of benzophenone [34].

The photochemistry mechanism of benzophenone occurred as shown in Figure 4. When the benzophenone compound absorbed ultraviolet light, the original structure of benzophenone undergoes singlet excitation, the protons from oxygen were transferred to carbon atoms, thus forming a photo tautomer into an enol structure. Molecules with an enol structure can then rearranged into the original compound through deactivation without radiation by releasing heat and returning to the initial state [34].

\subsection{Effects of Benzotriazole UV Absorber Addition}

Another type of UV absorber is used on cotton fabric which is dyed with natural dyes from Peristrophe bivalvis extract to increase the value of UV Protection Factor. UV absorber used was 2(2-hydroxy-5-methyl-phenyl)-2H-benzotriazole which is a derivative of benzotriazole. Physically, the samples treated with the addition of benzotriazole before and after dyeing looks a little darker. The color's shade of fabric samples with the addition of benzotriazole in various treatments and concentrations are shown in Table 2. Data on the value of protection against ultraviolet light (UPF) on fabrics dyed with natural dyes from Peristrophe bivalvis with the addition of benzophenone UV absorbers are presented in Figure 5.

Similar to the treatment of benzophenone, the addition of benzotriazole to the cotton fabric which is dyed with natural dyes from Peristrophe bivalvis extract, generally results in an increase in UPF value at each variation of the concentration of the UV absorber benzotriazole and its treatment process. In the concentration variation of benzotriazole, the greater the value of the concentration of 
benzotriazole, the better the UPF value, so that the protection of the fabric against ultraviolet is better. UPF values rise with increasing benzotriazole concentrations in each treatment adding benzotriazole, both before dyeing, after dyeing, or both.

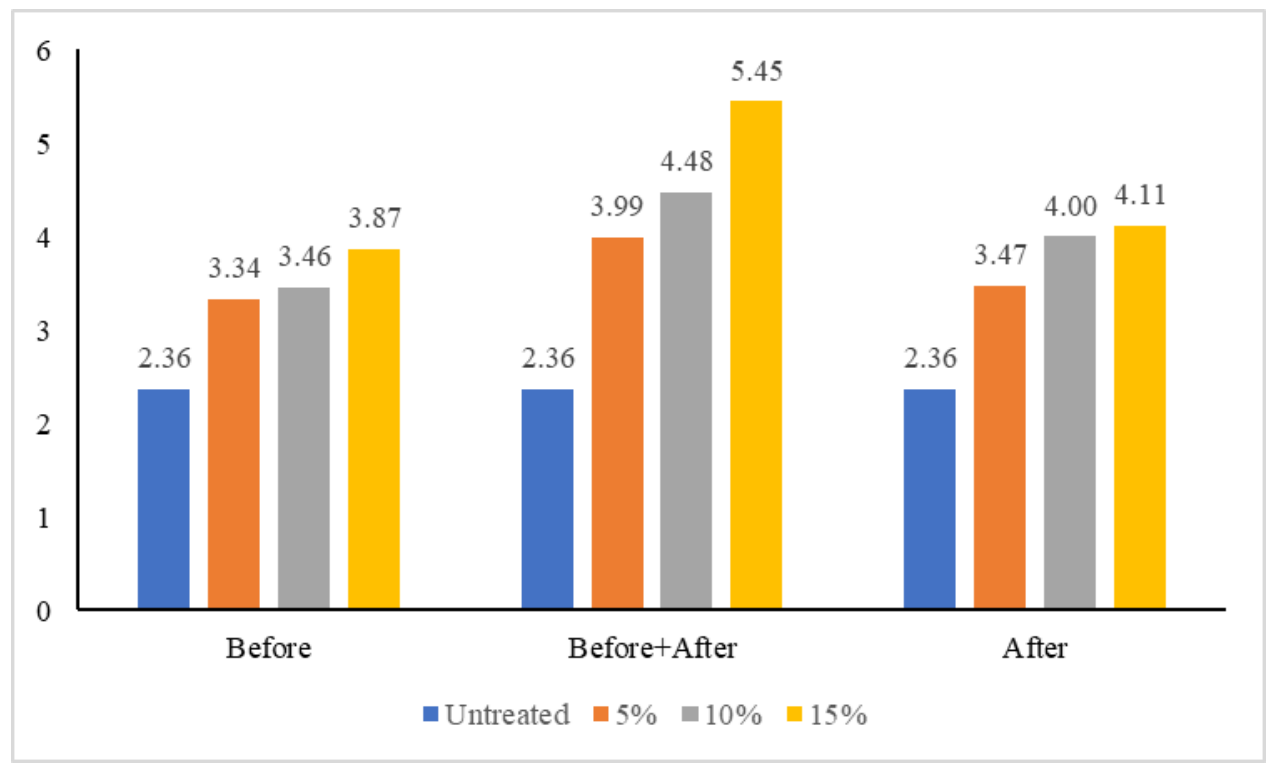

Fig. 5. UV Protection Factor of Cotton in additions of Benzotriazole

Table 2. The Shades of Dyed Cotton in Additions of Benzotriazole.

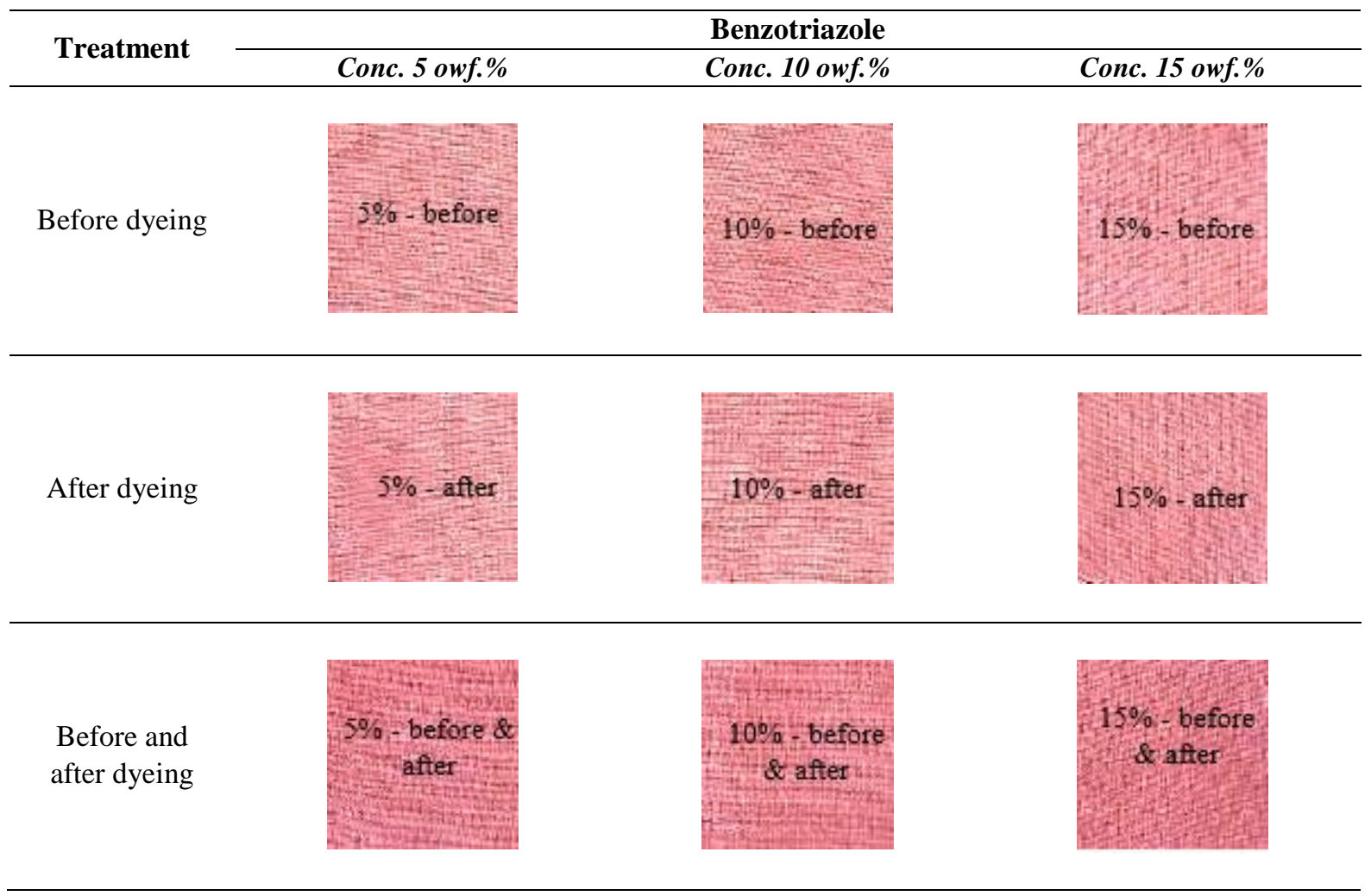

UPF values obtained by the addition of UV absorbers from benzotriazole are better than benzophenone, reaching at UPF values of 5.45. The highest UPF value was reached at a concentration of 15 owf. \% and in the treatment before and after dyeing. Tsatsaroni [35] in his study stated that this difference in the results of the UPF value is due to differences in the chemical 
structure of each UV absorber compound, the structure of the UV absorber in this study is presented in Figure 6. In the 2,4-Dihydroxybenzophenone or benzophenone has 2 polar hydroxyl groups, this group has a low affinity for dyes. While the benzotriazole has a methyl group that gives a higher affinity to the dye and increases the amount of dye absorbed into the cotton fabric.

The photochemistry mechanism of benzotriazole is presented in Figure 7. When the benzotriazole absorbs ultraviolet light, the original chemical structure of benzotriazole (in the form of enol form) experienced a singlet excitation, a transfer of protons from oxygen to the nitrogen atom, thus forming photo-tautomer (keto form). The keto form can then re-form the original compound through deactivation without radiation by releasing heat and returning to its initial state [36],[37].

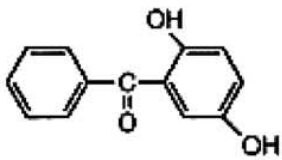

(a)

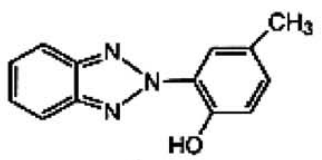

(b)

Fig. 6. Chemical structure of (a) 2,4-Dihydroxybenzophenone and (b) 2-(2-hidyroxy-.5-methyl-fenil)-2Hbenzotriazole. [35]

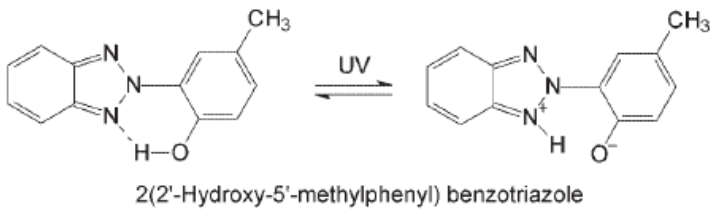

Fig. 7. Mechanism of benzotriazole photochemistry. [4]

\subsection{Lightfastness, washing fastness, and rubbing fastness}

The results of the fabric fastness test which were dyed with natural dyes from Peristrophe bivalvis extract with the addition of UV absorber treatment are presented in Table 3. The fastness tested are lightfastness, washing fastness, and rubbing fastness, using grayscale. The grayscale value ranging from 1 (worst rating) to 5 (excellent rating). Cotton fabrics that are dyed with natural dyes from Peristrophe bivalvis extract without the addition of UV absorbers have sufficient fastness to sunlight and wash with a grayscale value of 2-3 and good fastness to rubbing. The use of UV absorbers in fabric dyeing with natural dyes from Peristrophe bivalvis extract increases the value of lightfastness. The addition of the UV absorber additive slightly increases the quality of fabric fade resistance to sunlight with a grayscale value of 3 but does not increase the fastness to washing and rubbing.

Table 3. Fastness Results

\begin{tabular}{cccc}
\hline \multirow{2}{*}{ UV Absorber } & \multicolumn{3}{c}{ Fastness Tests } \\
\cline { 2 - 4 } & Lightfastness & Washing fastness & Rubbing fastness \\
\hline Without UV Absorber & $2-3$ & $2-3$ & $4-5$ \\
Bezophenone & 3 & $2-3$ & $4-5$ \\
Benzotriazole & 3 & $2-3$ & $4-5$ \\
\hline
\end{tabular}

\section{Conclusion}

The addition of UV absorbers to the dyed cotton with natural dyes from Peristrophe bivalvis extract increases the UPF value by before and after dyeing application treatment. The higher the UV absorber concentration, the better the UPF value result. The best UPF value was achieved with the addition of 15 owf. \% benzotriazole by before and after dyeing treatment with a UPF value of 5.45. The results of light fastness, washing fastness, and rubbing fastness ware also improved by the addition of UV absorber resulting in a grayscale of 3. 


\section{Acknowledgment}

Researchers would like to thank the Department of Chemical Engineering Universitas Gadjah Mada for the research facilities provided to run this experiment.

\section{References}

[1] M. Zimniewska and J. Batog, Ultraviolet-blocking properties of natural fibres. Woodhead Publishing Limited, 2012.

[2] M. Venturini et al., Ultraviolet Radiation: Both Friend and Foe in Systemic Autoimmune Diseases? Elsevier Inc., 2019.

[3] B. R. Das, "UV Radiation Protective Clothing," Open Text. J., vol. 3, pp. 14-21, 2010, doi: 10.1177/003591577006301023.

[4] W. D. Schindler and P. J. Hauser, Chemical finishing of textiles. 2004.

[5] A. Majumdar, A. Das, and P. Hatua, "Ultraviolet radiation protection by cotton fabrics: role of porous yarn structure, fabric thickness and pore size,” J. Text. Inst., vol. 107, no. 9, pp. 1159-1168, 2016, doi: 10.1080/00405000.2015.1097085.

[6] K. Hoffmann, J. Laperre, A. Avermaete, P. Altmeyer, and T. Gambichler, "Defined UV protection by apparel textiles," Arch. Dermatol., vol. 137, no. 8, pp. 1089-1094, 2001.

[7] P. Bajaj, V. K. Kothari, and S. B. Ghosh, "Some innovations in UV protective clothing," Indian J. Fibre Text. Res., vol. 25, no. 4, pp. 315-329, 2000.

[8] B. R. Das, S. M. Ishtiaque, R. S. Rengasamy, S. Hati, and A. Kumar, "Ultraviolet Absorbers for Textiles,” Res. J. Text. Appar., vol. 14, no. 1, pp. 42-52, 2010, doi: 10.1108/RJTA-14-01-2010B005.

[9] A. Kocić, M. Bizjak, D. Popović, G. B. Poparić, and S. B. Stanković, "UV protection afforded by textile fabrics made of natural and regenerated cellulose fibres," J. Clean. Prod., vol. 228, pp. 12291237, 2019, doi: 10.1016/j.jclepro.2019.04.355.

[10] D. Saravanan, “UV protection textile materials,” Autex Res. J., vol. 7, no. 1, pp. 53-62, 2007.

[11] U. Sayed, R. Tiwari, and P. Dabhi, "UV Protection Finishes on Textile Fabrics," Int. J. Adv. Sci. Eng., vol. 1, no. 3, pp. 56-63, 2015.

[12] R. Herrera, M. Muszyńska, T. Krystofiak, and J. Labidi, "Comparative evaluation of different thermally modified wood samples finishing with UV-curable and waterborne coatings," Appl. Surf. Sci., vol. 357, pp. 1444-1453, 2015, doi: 10.1016/j.apsusc.2015.09.259.

[13] O. K. Alebeid and T. Zhao, "Review on: developing UV protection for cotton fabric," J. Text. Inst., vol. 108, no. 12, pp. 2027-2039, 2017, doi: 10.1080/00405000.2017.1311201.

[14] R. Mongkholrattanasit, J. Kryštůfek, J. Wiener, and M. Vikov, "Dyeing, fastness, and uv protection properties of silk and wool fabrics dyed with eucalyptus leaf extract by the exhaustion process," Fibres Text. East. Eur., vol. 86, no. 3, pp. 94-99, 2011.

[15] P. Pisitsak, N. Tungsombatvisit, and K. Singhanu, "Utilization of waste protein from Antarctic krill oil production and natural dye to impart durable UV-properties to cotton textiles," J. Clean. Prod., vol. 174, pp. 1215-1223, 2018, doi: 10.1016/j.jclepro.2017.11.010.

[16] A. K. Sarkar, “An evaluation of UV protection imparted by cotton fabrics dyed with natural colorants," BMC Dermatol., vol. 4, pp. 1-8, 2004, doi: 10.1186/1471-5945-4-15.

[17] D. Gupta and Ruchi, "UPF characteristics of natural dyes and textiles dyed with them," Colourage, vol. 54, no. 4. pp. 75-80, 2007.

[18] N. Van Quan, D. T. Khang, L. T. Dep, T. N. Minh, N. Nobukazu, and T. D. Xuan, "The Potential Use of a Food-Dyeing Plant \&lt;i\&gt;Peristrophe bivalvis\&lt;/i\&gt; (L.) Merr. in Northern Vietnam," Int. J. Pharmacol. Phytochem. Ethnomedicine, vol. 4, pp. 14-26, 2016, doi: 10.18052/www.scipress.com/IJPPE.4.14.

[19] R. K. Hari, T. R. Patel, and A. M. Martin, "An overview of pigment production in biological systems: Functions, biosynthesis, and applications in food industry," Food Rev. Int., vol. 10, no. 1, 
pp. 49-70, 1994, doi: 10.1080/87559129409540985.

[20] T. T. Thuy et al., "Natural phenoxazine alkaloids from Peristrophe bivalvis (L.) Merr," Biochem. Syst. Ecol., vol. 44, pp. 205-207, 2012, doi: 10.1016/j.bse.2012.05.009.

[21] K. Phan, E. Van Den Broeck, V. Van Speybroeck, K. De Clerck, K. Raes, and S. De Meester, "The potential of anthocyanins from blueberries as a natural dye for cotton: A combined experimental and theoretical study," Dye. Pigment., vol. 176, p. 108180, 2020, doi: 10.1016/j.dyepig.2019.108180.

[22] Y. Yin, J. Jia, T. Wang, and C. Wang, “Optimization of natural anthocyanin efficient extracting from purple sweet potato for silk fabric dyeing," J. Clean. Prod., vol. 149, pp. 673-679, 2017, doi: 10.1016/j.jclepro.2017.02.134.

[23] P. Araújo et al., "Colour modulation of blue anthocyanin-derivatives. Lignosulfonates as a tool to improve the water solubility of natural blue dyes," Dye. Pigment., vol. 153, pp. 150-159, 2018, doi: 10.1016/j.dyepig.2018.02.019.

[24] H. Bahria and Y. Erbil, "UV technology for use in textile dyeing and printing: Photocured applications,” Dye. Pigment., vol. 134, pp. 442-447, 2016, doi: 10.1016/j.dyepig.2016.07.042.

[25] M. Shabbir, L. J. Rather, and F. Mohammad, "Economically viable UV-protective and antioxidant finishing of wool fabric dyed with Tagetes erecta flower extract: Valorization of marigold," Ind. Crops Prod., vol. 119, no. March, pp. 277-282, 2018, doi: 10.1016/j.indcrop.2018.04.016.

[26] R. T. Evitasari, E. Rahayuningsih, and A. Mindaryani, "Dyeing of cotton fabric with natural dye from peristrophe bivalvis extract," AIP Conf. Proc., vol. 2085, no. March, 2019, doi: 10.1063/1.5095033.

[27] The International Commission on Non-Ionizing Radiation Protection, "Guidelines on limits of exposure to ultraviolet radiation of wavelengths between $180 \mathrm{~nm}$ and $400 \mathrm{~nm}$ (incoherent optical radiation)," Health Phys., vol. 87, no. 2, pp. 171-186, 2004.

[28] Y. Shen, L. Zhen, D. Huang, and J. Xue, "Improving anti-UV performances of cotton fabrics via graft modification using a reactive UV-absorber," Cellulose, vol. 21, no. 5, pp. 3745-3754, 2014, doi: 10.1007/s10570-014-0367-3.

[29] J. Mamnicka and W. Czajkowski, "New fiber-reactive UV-absorbers increasing protective properties of cellulose fibres," Cellulose, vol. 19, no. 5, pp. 1781-1790, 2012, doi: 10.1007/s10570-012-9753-x.

[30] W. Czajkowski, J. Mamnicka, W. Lota, and J. Lewartowska, “Application of reactive UV-absorbers for increasing protective properties of cellulose fabrics during standard laundering process," Fibers Polym., vol. 13, no. 7, pp. 948-953, 2012, doi: 10.1007/s12221-012-0948-4.

[31] J. Paluszkiewicz, W. Czajkowski, M. Kaźmierska, and R. Stolarski, "Reactive dyes for cellulose fibres including UV absorbers,” Fibres Text. East. Eur., vol. 13, no. 2, pp. 76-80, 2005.

[32] C. W. Kan and C. H. Au, "Effect of biopolishing and UV absorber treatment on the UV protection properties of cotton knitted fabrics," Carbohydr. Polym., vol. 101, no. 1, pp. 451-456, 2014, doi: 10.1016/j.carbpol.2013.09.044.

[33] W. Chen, Z. Wang, Z. Cui, D. Pan, and K. Millington, "Improving the photostability of silk using a covalently-bound UV absorber,” Polym. Degrad. Stab., vol. 121, pp. 187-192, 2015, doi: 10.1016/j.polymdegradstab.2015.09.007.

[34] D. Cristea and G. Vilarem, "Improving light fastness of natural dyes on cotton yarn," Dye. Pigment., vol. 70, no. 3, pp. 238-245, 2006, doi: 10.1016/j.dyepig.2005.03.006.

[35] E. G. Tsatsaroni and I. C. Eleftheriadis, "UV-absorbers in the dyeing of polyester with disperse dyes,” Dye. Pigment., vol. 61, no. 2, pp. 141-147, 2004, doi: 10.1016/j.dyepig.2003.10.002.

[36] K. Dietliker, Photochemistry, vol. 38. Cambridge: RSC Publishing, 2011.

[37] H. I. Ibrahim, R. Farouk, E. A. El-Kharadly, A. H. M. Elwahy, and A. A. Mousa, "Synthesis, characterization and application of reactive UV absorbers for enhancing UV protective properties of cotton fabric,” Egypt. J. Chem., vol. 63, no. 2, pp. 525-536, 2020, doi: 10.21608/ejchem.2020.22140.2324. 